ISSN 1997-5902

\title{
In vitro evaluation of the effect of aqueous extracts of Agave sisalana and Cymbopogon citratus on mycelial growth and conidia production of Pyricularia oryzae, causal agent of rice blast
}

\author{
Abalo Itolou KASSANKOGNO1*, Ibrahima OUEDRAOGO1', Assita TIENDREBEOGO², Leonard \\ OUEDRAOGO ${ }^{2}$ and Philippe SANKARA ${ }^{3}$ \\ $1^{*}$ University of Ouagadougou, Graduate School of Science and Technology, Laboratory of Biosciences, 03 PO BOX \\ 7021 Ouagadougou 03 Burkina Faso \\ 1 Environment and Agricultural Research Institute, BP 910BoboDioulasso. \\ *Email the corresponding author kassinera@yahoo.fr/kassabalo@yahoo.fr
}

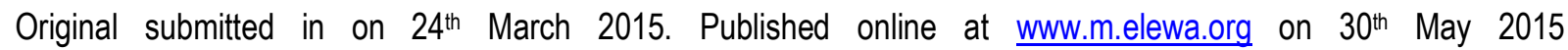
http://dx.doi.org/10.4314/jab.v89i1.7

\begin{abstract}
Objectives: To evaluate the effects of aqueous extracts of Agave sisalana (sisal) and Cymbopogon citratus (lemon grass) on mycelial growth and conidia production of Pyricularia oryzae, causal agent of Rice Blast.

Methodology and Results: The plants aqueous extracts were used at concentrations $0.1 ; 0.2 ; 0.3 ; 0.4 ; 0.5 ; 1 ; 2$; $3 ; 4 ; 5 ; 10 ; 20 ; 30 \%$ concentrations for Agave sisalana extracts and $0.5 ; 3 ; 5 ; 10 ; 15 ; 20 \%$ for C. citratus extracts. Fisher randomized block design with five (5) replicates was used to test the two extracts. All the two extracts tested had an inhibitory effect on the growth and spore production of the fungus. The Minimum inhibitory concentration (MIC) of Agave sisalana extracts was $3 \%$ (PI $\leq 97 \%)$.For the $C$. citratus extract, the MIC was $20 \%$ and the concentration less than $20 \%$ had a mild effect on mycelial growth.

Conclusion and application potential of the results: The use of pesticides of plant origin has been suggested by some researchers as alternatives to synthetic chemicals, in order to counter the potential hazards and pollution problems associated with the use of synthetic chemicals. The plants extracts tested showed antifungal activity. This result should enable use of aqueous extract of Agave sisalana to control blast diseases.
\end{abstract}

Key words: In vitro, plant extracts, mycelial growth, spore production, rice blast, Pyricularia oryzae.

\section{INTRODUCTION}

Rice (Oryza sativa L.) is one of the most important cereals in the world and is consumed by $50 \%$ of the world population (FAO, 2012). In Burkina Faso, the total rice production covers about $30 \%$ of the needs of the country. This situation is mainly due to the very low productivity of rice fields. Among the diverse constraints that rice producers face, diseases are causing serious yield losses. Rice blast caused by Pyricularia oryzae Cavara [synonym Pyricularia grisea Sacc. the anamorph of Magnaporthe grisea (Herbert) Yaegashi and Udagawa], is one of the most destructive and widespread diseases (Jia et al., 2000). This disease has caused significant yield losses in many rice-growing countries: heavy yield losses (up to $100 \%$ ) were reported by farmers in Ghana (Nutsugah et al.,2004) and in some locations in The Gambia (Jobe et al., 2002). In Japan the yield loss due to blast constituted $45.9 \%$ of the total loss 
induced by all diseases (MAFF 2012); 36-63\% in Burkina Faso , 64\% in Togo and up to $80 \%$ in Côte d'Ivoire (Séré et al ,2013). In Burkina Faso, rice blast is considered as one of the major yield constraints (Sere et al, 2007). The disease can be managed by the use of fungicides, resistant cultivars, agronomic practices and biotechnological methods (Ribot et al., 2008). Chemicals are commonly applied for controlling rice blast disease (Anwar et al., 2002; Oh, 2007; Gohel et al. , 2008). However, the frequent use of fungicides on crops may cause hazards to human beings, plant health, useful microorganisms, and develop fungicide resistance in the pathogens populations. Moreover, some botanical pesticides have proved to be most secure and to have reduced adverse impact on the environment (Iftikhar et al., 2010; Babar et al., 2011). The use of pesticides of plant origin has been suggested by some researchers as alternatives to synthetic chemicals, in order to counter the potential hazards and pollution problems associated with the use of synthetic chemicals (Amadioha, 2000). Sisal is a perennial succulent plant that belongs to the family of Asparagaceae (Figure 1B). It is cultivated as a source of fibres traditionally used in the production of twine, ropes, carpets, mattresses and handicrafts. Leaf waste also has been used as a material to produce bio-fuel (methane). This species is also used as "live fences" or as an ornamental plant in gardens. Other products developed from sisal fibres include spa and cosmetic products, cat scratching posts, lumbar support belts, rugs, slippers, and cloths (FAO, 2012; PROTA, 2012). Some potential innovations include the use of the material as an organic fertilizer, a supplement in ruminant feed (Bandeira and Silva, 2006) and a raw material in the production of medicine ( Debnath et al., 2010). In Africa, extracts of $A$. sisalana leaves and leaf waste are used in traditional medicine as a fungicide. A study evaluating the antimicrobial activity of extracts of the leaves and leaf waste discarded in the process of obtaining the hard fibres of $A$. sisalana showed significant inhibition of Candida albicans when treated with sisal extracts (Santos et al., 2009).

Lemon grass is originating from Indonesia and belongs to the family of Poaceae (Figure 1A). This plant is a widely used herb in tropical countries. The compounds identified in Cymbopogon citratus are mainly terpenes, alcohols, ketones, aldehyde and esters. Some of the reported phytoconstituents are essential oils that contain Citral $\alpha$, Citral $\beta$, Nerol Geraniol, Citronellal, Terpinolene, Geranyl acetate, Myrecene and Terpinol Methylheptenone. The plant also contains reported phytoconstituents such as flavonoids and phenolic compounds, which consist of luteolin, isoorientin 2'-O-rhamnoside, quercetin, kaempferol and apiginin. Studies indicate that Cymbopogon citratus possesses various pharmacological activities such as anti-amoebic, antibacterial, antidiarrheal, antifilarial, antifungal and anti-inflammatory properties. (PubMed,2011). Others studies indicate the positive effect of plant extracts in inhibiting mycelia growth. The results of $P$. grisea growth on PDA amended with plant extracts showed that $A$. indica, $A$. vera, $A$. sativum, $C$. arabica, $C$. coccineum, D. stramonium, C. sinensis, Z officinalis and $N$. tabacum had antifungal properties against $P$. grisea at high $(25 \%)$ but not at low (1\%) concentrations in in-vitro. Therefore, the efficacy of plant extracts needs to be investigated. In the present study, the aqueous extract of $A$. sisalana (sisal) and $C$. citratus (lemon grass) have been used in vitro to test the inhibition of mycelial growth and the spore production of $\mathrm{P}$. oryzae, the causal agent of rice blast. 

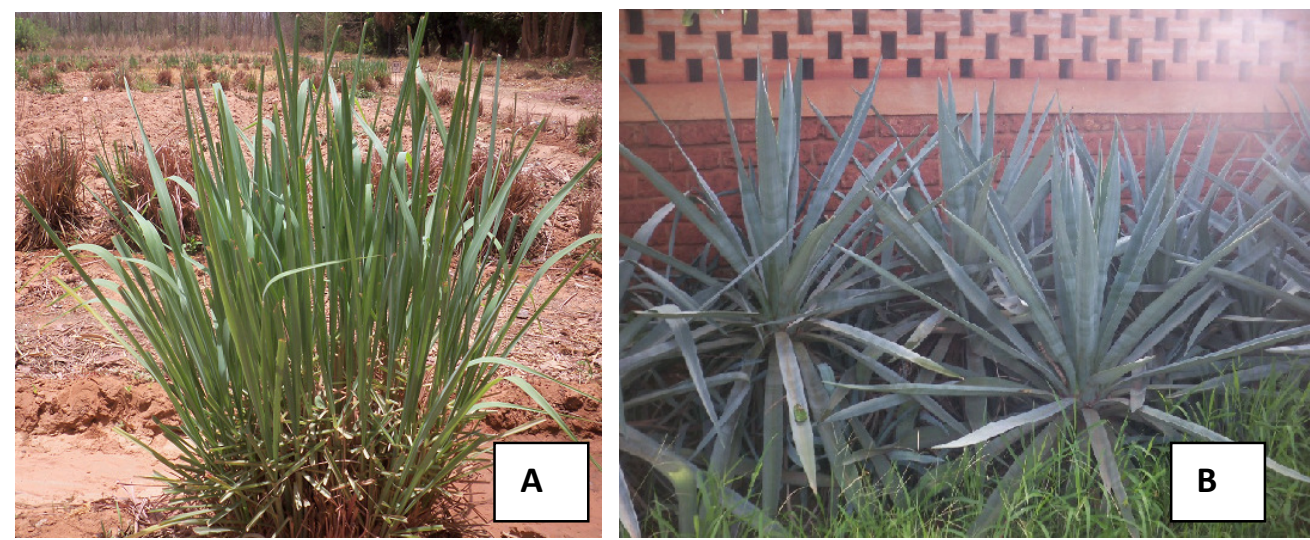

Figure 1 : (A) C. citratus (lemon grass) plant et ( B) A. sisalana (sisal) plant

\section{MATERIALS AND METHODS}

Collection and culture of fungal material: Blast lesions on diseased or infected leaves were used for the collection of $P$. oryzae spores (Figure 2A). These diseased organs were incubated on moist filter papers in Petri plates at room temperature and incubated under alternating cycles of 12 hours near ultra-violet (NUV) light and 12 hours darkness for 48 hours to induce spores production (Figure $2 \mathrm{~B}$ ). The conidia from the lesion surface were spread onto $3 \%$ water agar with a sterile loop and incubated overnight (Figure 2C). Single germinating conidia were isolated and grown on potatodextrose agar (PDA) medium for 5-10 days.

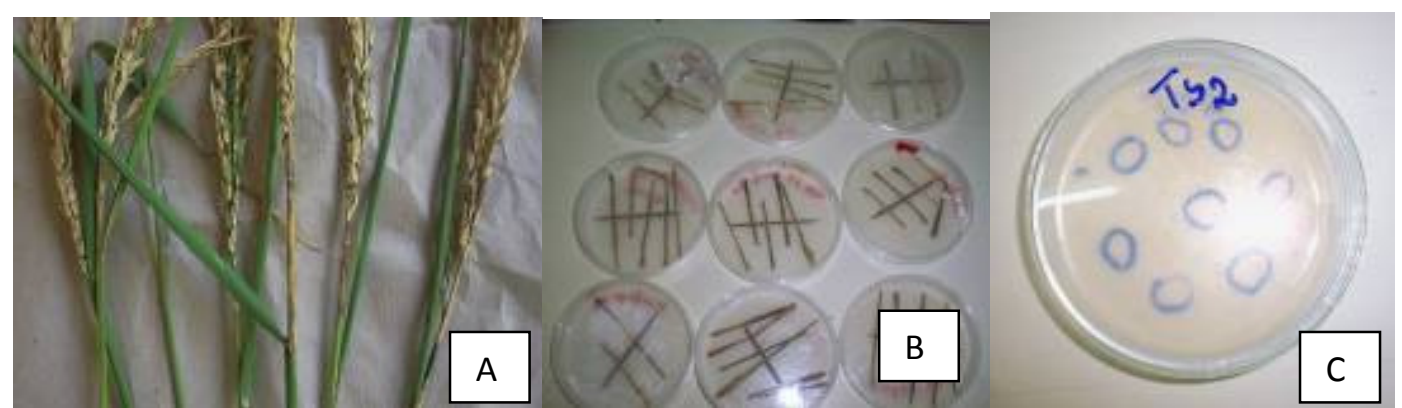

Figure 2: (A) infected sample (B) incubation (C) isolation of conidia.

Preparation of plant extract and culture media: The aqueous extracts of $A$. sisalana were obtained from dried roots and C. citratus from dried leaves. The dried roots and the leaves were mechanically reduced. The aqueous extracts were prepared by soaking $1 ; 2 ; 3 ; 4 ; 5 ; 10 ; 15$; $20 ; 30 \mathrm{~g}$ of plant powder in $100 \mathrm{ml}$ of distilled water for 24 hours at room temperature $\left(25-28^{\circ} \mathrm{C}\right)$ (Figure $\left.3 \mathrm{a}\right)$. These different quantities were equivalent to $1 ; 2 ; 3 ; 4 ; 5 ; 10 ; 15$; 20 and $30 \%$. For concentrations lower than $1 \%$, stock solution (10) was diluted. In addition, $100 \mathrm{ml}$ of the filtrate was added to $4.2 \mathrm{~g}$ PDA. The studied concentrations were $0.1,0.2,0.3,0.4,0.5,1,2,3,4,5,10,20$ and, $30 \%$ for A. sisalana (sisal) and $0.5,3,5,10,15$, and $20 \%$ for $C$. citratus. The culture medium was autoclaved at $121^{\circ} \mathrm{C}$ for 15 minutes and then poured into $9 \mathrm{~cm}$ diameter Petri plates (Figure 3b). After the solidification of the medium, 5 $\mathrm{mm}$ disc of pure culture of the test fungus (P. oryzae) was placed in the center of Petri plates and incubated at 30 oC (Figure $3 \mathrm{c}$ ). Plates of PDA without aqueous extract served as controls. There were five replications of each treatment. 

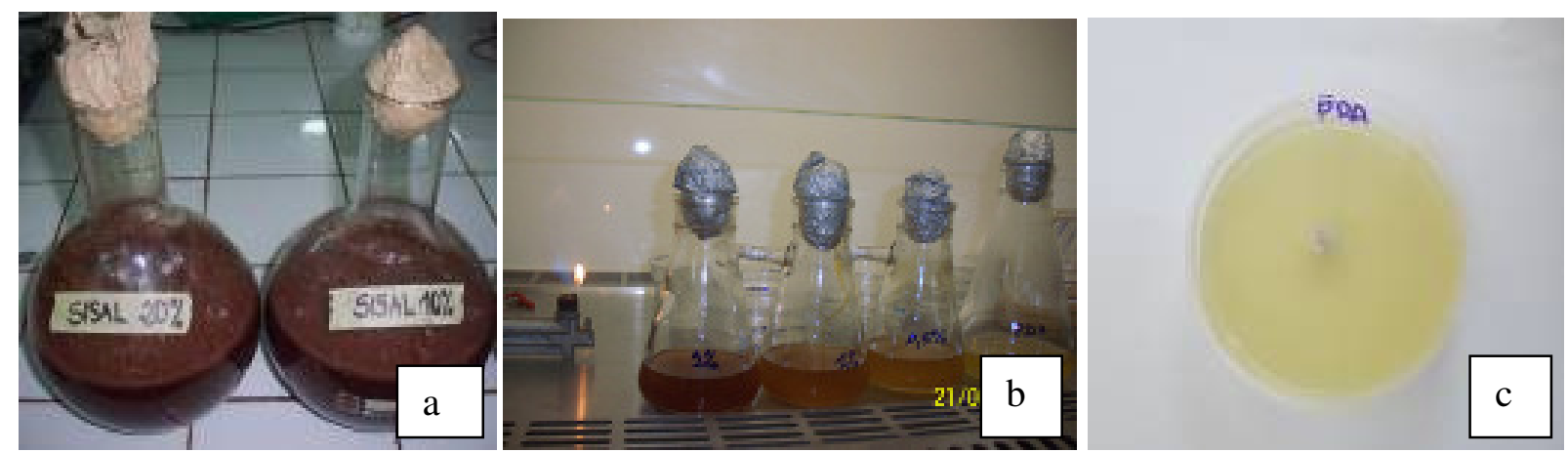

Figure3: Extract of $A$. sisalana (a); culture media preparation (b); inoculation (c)

Evaluation of mycelial growth: Radial mycelial growth of the test fungus was measured at right angles on the different concentrations the $3 \mathrm{rd}$, 5th, 7th, 10th 12th and 14th days after incubation (DAI) (Figure 4).Percentage of inhibition of mycelial growth by plant extracts was calculated using the formula: \% inhibition of mycelia growth $=(D C-D T) \times 100 / D C$ Where $D C=$ mean diameter of control DT= mean diameter of test
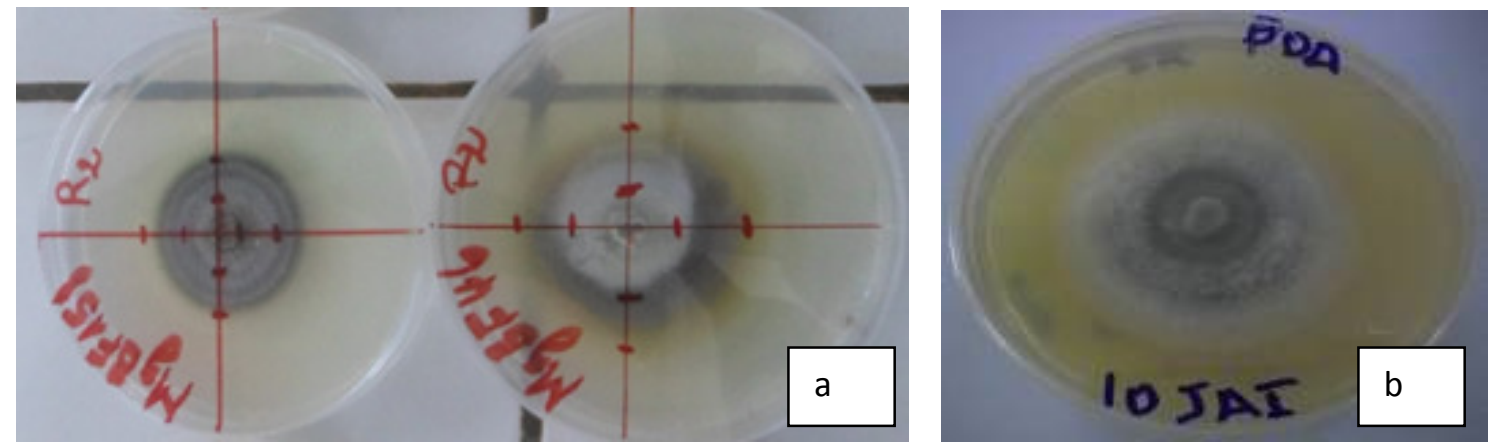

Figure 4: Evaluation of mycelial growth of Pyricularia oryzae ( $a$ and $b$ )

Evaluation of fungus spore production on different concentrations of plant extract: After day 14, the colony mycelium of $P$. oryzae containing the spores was scraped into a test tube and the content was filtered using a filter. Spore production counting was conducted using Thomas cell. The volume used to extract the spores was $10 \mathrm{ml}$ and the count was conducted at a magnification of 40.

\section{RESULTS AND DISCUSSION.}

Effectiveness of Agave sisalana and Cymbopogon citratus extracts on mycelium growth of Pyricularia oryzae:The data indicated that the different treatments had a repressive effect on fungal growth rate. The statistical analysis revealed statistically significant differences among several groups $(P<0$. 0001). The general observation showed that $18 \mathrm{DAl}$, the control (TO)
Experimental design and data analysis: The test was conducted according to Fisher randomized block design with five (5) replicates for the two tested extracts. For $A$. sisalana extracts, fourteen (14) treatments were used while for $C$. citratus extracts seven (07) treatments were used. Data were analyzed by the software XIstat-Pro using analysis of variance (ANOVA) and mean differences were separated at $p \leq 0.05$ level of significabce using Newman Keuls test.

had recorded the highest radial growth $(7 \mathrm{~cm})$. The $3 \%$ concentration of the extract of $A$. Sisalana (T8) appeared to be the minimum inhibitory concentration of radial growth of $P$. oryzae. Above this concentration, no fungal growth was observed. 
Kassankogno et al. . J. Appl. Biosci. In vitro evaluation of the effect of aqueous extracts of Agave sisalana and Cymbopogon citratus on mycelial growth and conidia production of Pyricularia oryzae, causal agent of rice blast

Table 1: Effect of Agave sisalana extracts on mycelial growth of Pyricularia oryzae

\begin{tabular}{|c|c|c|c|c|c|c|c|}
\hline Treatment & 3DAI & 5DAI & 7DAI & 10DAl & 12DAI & 15DAI & 18DAl \\
\hline TO (PDA) & $0.85 b$ & $1.51 a$ & $2.18 a$ & $3.53 a$ & $4.56 a$ & $5.78 \mathrm{a}$ & $7.50 a$ \\
\hline $\mathrm{T} 1$ (0.1\%AS) & $0.90 a$ & $1.45 a$ & $2.08 b$ & $3.31 b$ & $4.16 \mathrm{~b}$ & $5.35 b$ & $7.11 b$ \\
\hline T2 (0.2\%AS) & $0.76 \mathrm{c}$ & $1.15 b$ & $1.65 \mathrm{c}$ & $2.41 \mathrm{c}$ & $3.45 \mathrm{c}$ & $4.46 \mathrm{c}$ & $5.86 \mathrm{c}$ \\
\hline T3 (0.3\%AS) & $0.70 \mathrm{~d}$ & $0.96 \mathrm{c}$ & $1.35 d$ & $2.16 d$ & $2.96 \mathrm{~d}$ & $3.58 \mathrm{~d}$ & $4.70 \mathrm{~d}$ \\
\hline T4 (0.4\%AS) & $0.60 \mathrm{e}$ & $0.86 \mathrm{~cd}$ & $1.21 \mathrm{e}$ & $1.86 \mathrm{e}$ & $2.55 \mathrm{e}$ & $3.18 \mathrm{e}$ & $4.08 \mathrm{e}$ \\
\hline T5 (0.5\%AS) & $0.60 \mathrm{e}$ & $0.80 \mathrm{~d}$ & $1.06 f$ & $1.50 f$ & $2.28 f$ & $2.68 f$ & $3.80 f$ \\
\hline T6 (1\%AS) & $0.00 \mathrm{f}$ & $0.66 \mathrm{e}$ & $0.80 \mathrm{~g}$ & $1.16 \mathrm{~g}$ & $1.45 \mathrm{~g}$ & $1.55 \mathrm{~g}$ & $2.11 \mathrm{~g}$ \\
\hline T7 (2\%AS) & $0.00 f$ & $0.66 \mathrm{e}$ & $0.78 \mathrm{~g}$ & $0.85 \mathrm{~h}$ & $0.93 \mathrm{~h}$ & $1.08 \mathrm{~h}$ & $1.18 \mathrm{~h}$ \\
\hline T8 (3\%AS) & $0.00 f$ & $0.00 f$ & $0.00 \mathrm{~h}$ & $0.00 \mathrm{i}$ & $0.00 \mathrm{i}$ & $0.00 \mathrm{i}$ & $0.00 \mathrm{i}$ \\
\hline T9 (4\%AS) & $0.00 f$ & $0.00 f$ & $0.00 \mathrm{~h}$ & $0.00 \mathrm{i}$ & $0.00 \mathrm{i}$ & $0.00 \mathrm{i}$ & $0.00 \mathrm{i}$ \\
\hline T10 (5\%AS) & $0.00 f$ & $0.00 f$ & $0.00 \mathrm{~h}$ & $0.00 \mathrm{i}$ & $0.00 \mathrm{i}$ & $0.00 \mathrm{i}$ & $0.00 \mathrm{i}$ \\
\hline T11 (10\%AS) & $0.00 f$ & $0.00 f$ & $0.00 \mathrm{~h}$ & $0.00 \mathrm{i}$ & $0.00 \mathrm{i}$ & $0.00 \mathrm{i}$ & $0.00 \mathrm{i}$ \\
\hline T12 (20\%AS) & $0.00 f$ & $0.00 f$ & $0.00 \mathrm{~h}$ & $0.00 \mathrm{i}$ & $0.00 \mathrm{i}$ & $0.00 \mathrm{i}$ & $0.00 \mathrm{i}$ \\
\hline T13 (30\%AS) & $0.00 \mathrm{f}$ & $0.00 f$ & $0.00 \mathrm{~h}$ & $0.00 \mathrm{i}$ & $0.00 \mathrm{i}$ & $0.00 \mathrm{i}$ & $0.00 \mathrm{i}$ \\
\hline Value of $F$ & 487.61 & 241.46 & 587.65 & 345.21 & 791.16 & 886.17 & 1579.58 \\
\hline Probability & 0.0001 & 0.0001 & 0.0001 & 0.0001 & 0.0001 & 0.0001 & 0.0001 \\
\hline Level of signification & VHS & VHS & VHS & VHS & VHS & VHS & VHS \\
\hline
\end{tabular}

Values with the same letter on the same column have no significant differences at $5 \%$ level (Newman-Keuls test). VHS: Very Highly Significant. T0: control PDA; T1-T13: different concentrations of Agave sisalana extract; AS Agave sisalana; DAl: Day After Incubation.

Table 2: Effect of Cymbopogon citratus extracts on mycelium growth of Pyricularia oryzae

\begin{tabular}{|c|c|c|c|c|c|}
\hline Treatment & 3DAl & 5DAl & 7DAl & 10DAl & 12DAl \\
\hline T0 (PDA) control & $1.283 b$ & $2.167 \mathrm{c}$ & $3.200 \mathrm{c}$ & $4.850 \mathrm{c}$ & $6.267 \mathrm{~b}$ \\
\hline $\mathrm{T} 1(0.5 \% \mathrm{Cc})$ & $1.417 \mathrm{~b}$ & $2.667 \mathrm{~b}$ & $3.683 b c$ & 5.767ab & $7.217 \mathrm{a}$ \\
\hline $\mathrm{T} 2(3 \% \mathrm{Cc})$ & $1.633 a$ & $3.117 a$ & $4.433 a$ & $6.233 a$ & $7.567 a$ \\
\hline T3(5\%Cc) & $1.433 b$ & $2.850 \mathrm{~b}$ & $3.683 b c$ & $5.283 b c$ & $6.183 b$ \\
\hline $\mathrm{T} 4(10 \% \mathrm{Cc})$ & $1.050 \mathrm{c}$ & $2.117 \mathrm{c}$ & $3.250 \mathrm{c}$ & $5.167 c$ & $5.050 \mathrm{c}$ \\
\hline $\mathrm{T} 5(15 \% \mathrm{Cc})$ & $0.500 d$ & $1.433 d$ & $2.300 d$ & $4.050 \mathrm{~d}$ & $4.333 \mathrm{c}$ \\
\hline $\mathrm{T} 6(20 \% \mathrm{Cc})$ & $0.000 \mathrm{e}$ & $0.000 \mathrm{e}$ & $0.000 \mathrm{e}$ & $0.000 \mathrm{e}$ & $0.000 \mathrm{~d}$ \\
\hline Value of $F$ & 184.002 & 172.405 & 105.170 & 135.555 & 96.049 \\
\hline Probability & 0.0001 & 0.0001 & 0.0001 & 0.0001 & 0.0001 \\
\hline Level of signification & VHS & VHS & VHS & VHS & VHS \\
\hline
\end{tabular}

Values with the same letter on the same column have no significant differences at $5 \%$ level (Newman-Keuls test). VHS: Very Highly Significant. T0: control (PDA); T1-T6: different concentrations of Cymbopogon citratus extract; Cc: Cymbopogon citratus; DAI: Day After Incubation.

Different concentrations of $C$. citratus extracts yielded very highly significant different mycelia growth $(P<0$. 0001). The different aqueous extracts of $C$. citratus had a repressive effect on fungal growth. All studied treatments showed that the concentrations less than $5 \%$ enhanced the mycelium growth of $P$. oryzae. The $20 \%$ concentration (T6) proved to be the MIC along of experiment period. 
Effectiveness of Agave sisalana and Cymbopogon citratus extracts on spore production of Pyricularia oryzae: The result showed that the number of spores counted 10 DAl was dependant on the concentrations of A. sisalana extract. The results of the analysis of variance showed very high significant $(P<0.0001)$ differences between treatments for the number of conidia. Five statistically different groups were distinguished between treatments based on the number of spore counted. T0
(PDA) ; T1 (0.1\%AS) and T2(0.2\%AS) had inhibition percentages lower than $20 \%$. As for T3 (0.3\%AS); T4 (0.4\%AS); T5(0.5\%AS); T6(1\%AS) and T7( $2 \% \mathrm{AS})$, they had inhibition percentages between $60 \%$ and $97 \%$ while T8 (3\% AS), T9 (4\%AS), T10 (5\%AS), T11 (10\%AS), T12 (20\% AS), T13 (30\%AS) inhibited spore production and T8 was therefore considered as the MIC for spore production.

Table 3: Effect of Agave sisalana aqueous extracts on spore production of Pyricularia oryzae

\begin{tabular}{|l|l|l|}
\hline Treatment & $\begin{array}{l}\text { Number of spores/ml } \\
\text { (10 JAI) }\end{array}$ & Inhibition Percentage (PI) (10DAl) \\
\hline T0 (PDA) control & $3.52510^{5} \mathrm{a}$ & $0.00 \mathrm{c}$ \\
\hline T1 (0.1\%AS) & $3.17510^{5} \mathrm{ab}$ & $7.46 \mathrm{c}$ \\
\hline T2 (0.2\%AS) & $2.80010^{5} \mathrm{~b}$ & $18.08 \mathrm{c}$ \\
\hline T3 (0.3\%AS) & $1.25010^{5} \mathrm{c}$ & $63.50 \mathrm{~b}$ \\
\hline T4 (0.4\%AS) & $6.75010^{4} \mathrm{~d}$ & $79.19 \mathrm{a}$ \\
\hline T5 (0.5\%AS) & $4.47010^{4} \mathrm{de}$ & $86.45 \mathrm{a}$ \\
\hline T6 (1\%AS) & $3.50010^{4} \mathrm{de}$ & $89.42 \mathrm{a}$ \\
\hline T7 (2\%AS) & $1.00010^{4} \mathrm{de}$ & $97.09 \mathrm{a}$ \\
\hline T8 (3\%AS) & $0.000 \mathrm{e}$ & $100 \mathrm{a}$ \\
\hline T9 (4\%AS) & $0.000 \mathrm{e}$ & $100 \mathrm{a}$ \\
\hline T10 (5\%AS) & $0.000 \mathrm{e}$ & $100 \mathrm{a}$ \\
\hline T11 (10\%AS) & $0.000 \mathrm{e}$ & $100 \mathrm{a}$ \\
\hline T12 (20\%AS) & $0.000 \mathrm{e}$ & $100 \mathrm{a}$ \\
\hline T13 (30\%AS) & $0.000 \mathrm{e}$ & $100 \mathrm{a}$ \\
\hline Value of F & 73.65 & 49.29 \\
\hline Probability & 0.0001 & 0.0001 \\
\hline Level of signification & VHS & VHS \\
\hline
\end{tabular}

The evaluation of the effect of lemon grass on spore production after 10 days of incubation revealed that only the $20 \%$ concentration (T6) was effective. The analysis of variance of the conidia count for the treatments revealed a very highly significant difference $(P<0.0001)$ between treatments. The 10\% "concentration (T4) and 15\% concentration (T5) produced less spores compared to
$0.5 \%$ concentration ( $\mathrm{T} 1$ ) and $3 \%$ concentration ( $\mathrm{T} 2$ ). The control T0 (PDA) produced the highest spore production. The results of the table show that the concentration between $0.5 \%$ and $15 \%$ had a partial inhibition of spore production compared to $20 \%$ concentration (T6) whose inhibition is complete $(100 \%)$. 

blast

Table 4: Effect of Cymbopogon Citratus aqueous extract on the spore production of Pyricularia oryzae

\begin{tabular}{|l|l|l|}
\hline Treatment & $\begin{array}{l}\text { Number of spores } / \mathrm{ml} \\
\text { (10DAl) }\end{array}$ & Inhibition Percentage (PI) (10DAl) \\
\hline T0 (PDA) & $1.55510^{6} \mathrm{a}$ & $0.00 \mathrm{e}$ \\
\hline T1 $(0.5 \% \mathrm{Cc})$ & $1.45010^{6} \mathrm{~b}$ & $6.75 \mathrm{~d}$ \\
\hline T2 $(3 \% \mathrm{Cc})$ & $6.35010^{5} \mathrm{c}$ & $59.15 \mathrm{c}$ \\
\hline T3 $(5 \% \mathrm{Cc})$ & $1.60010^{5} \mathrm{~d}$ & $89.70 \mathrm{~b}$ \\
\hline T4 $(10 \% \mathrm{Cc})$ & $3.50010^{4} \mathrm{e}$ & $97.75 \mathrm{a}$ \\
\hline T5 $(15 \% \mathrm{Cc})$ & $2.50010^{4} \mathrm{e}$ & $98.39 \mathrm{a}$ \\
\hline T6 $(20 \% \mathrm{Cc})$ & $0.000 \mathrm{e}$ & $100.00 \mathrm{a}$ \\
\hline Value of $\mathrm{F}$ & 1829.519 & 1761.432 \\
\hline Probability & 0.0001 & 0.0001 \\
\hline Level of signification & VHS & VHS \\
\hline
\end{tabular}

Values with the same letter on the same column have no significant differences at $5 \%$ level (Newman-Keuls test). VHS: Very Highly Significant. T0: control PDA; T1-T6: different concentration of Cymbopogon citratus; C c: Cymbopogon citratus; DAl: Day After Incubation; PI: Percentage of Inhibition;

\section{DISCUSSION}

The colony growth and spore production of P. oryzae was gradually reduced with increasing concentrations of the aqueous extracts. The reduction of the diameter of mycelial colonies of test fungus in the presence of the extract of $A$. sisalana and $C$. citratus showed that there is an active principle in antifungal properties that inhibit the growth of the test fungus. This inhibitory effect varies according to plant species, plant age and plant part and/or to applied concentration. The tests with A. sisalana aqueous extract showed that low concentrations (less than $3 \%$ ) inhibited partially the mycelial growth of the fungus but higher concentration inhibited completely the growth of the parasite. The in vitro effect of aqueous extracts of $A$. sisalana on spore production of $P$. oryzae showed that low concentrations (less than 3\%) partially inhibited the spore or conidia production of the fungus with a percent inhibition (PI) that was less than $100 \%$. On the other hand, high concentrations (higher than $3 \%$ )

\section{CONCLUSION}

Aqueous extracts of $A$. sisalana and $C$. citratus proved their antifungal activity by mycelial growth and spore production of $P$. oryzae. This extract also showed an inhibitory effect on spore production at the low concentration. The extract of $C$. citratus at high concentration ( $\geq 20 \%$ ) inhibited completely the mycelial growth and spore production of $P$. oryzae. However, low concentrations $(<20 \%)$, provided moderately reduction in the mycelial growth of the fungus. Therefore, an have completely inhibited the spore production with a percent inhibition (PI) was $100 \%$. These results confirm those reported by Jener and al (2009) and Ade-Ajayi and al (2011) whose reported that Agave sisalana juice revealed the presence of alkaloids, terpenoids, flavonoids, tannins, saponins and cardiac glycosides, which have been found in vitro to have antimicrobial properties in vitro. The effect of aqueous extract of $C$. citratus on the mycelial growth and conidia production showed that high concentrations (greater than $20 \%$ ), inhibited completely the mycelial growth and conidia production of $P$. oryzae but the low concentrations (less than $20 \%$ ), provided moderately reduction in the mycelial growth of the fungus. These results confirm those reported by Somda et al (2007) who observed that the concentration of $\mathrm{C}$. citratus below $30 \%(\geq 30 \%)$ were inefficient to control P. sorghina and C. graminicola whereas concentrations above $30 \%$ were efficient.

inappropriate use of this extract has dramatic consequences especially as it is the vegetative form of the fungus that is responsible for damage observed in the field. In spite of the in vitro efficiency of the extracts from plants, further experiments on their ability to control disease in greenhouse and in field to assess an efficient concentration of control of $P$. oryzae. Furthermore, the identification and characterization of the active compound will also be useful in the process of biopesticides 
production. Research on the range of activity of plant extracts for control of other rice pathogens is

\section{ACKNOWLEDGEMENTS:}

The authors wish to express their sincere thanks to the Institute of Environment and Agricultural Research (INERA), for providing the financial support to carry out the

\section{REFERENCES}

Acevedo-Rodríguez P, Strong MT, 2005. Monocots and Gymnosperms of Puerto Rico and the Virgin Islands. Contributions from the United States National Herbarium, 52:1-416.

Ade-Ajayi A. F, Hammuel C, Ezeayanaso C, Ogabiela E. E, Udiba U. U, Anyim B. and Olabanji O. 2011. Preliminary phytochemical and antimicrobial screening of Agave sisalana Perrine juice (waste) Journal of Environmental Chemistry and Ecotoxicology Vol. 3(7), pp. 180-183, July 2011 Available online http://www.academicjournals.org/jece ISSN2141-226X @ 2011 Academic Journals.

Amadioha AC, 2000. Controlling rice blast In vitro and In vivo with extracts of Azadirachta indica. Crop Prot., 19(5): 287-290.

Anwar A, Bhat GN, Singhara GN, 2002. Management of sheath blight and blast in rice through seed treatment. Ann. PI. Protec. Sci., 10: 285-287.

Awodera V A and Esuruoso O F, 1975. Reduction in grain yield of two rice varieties infected by rice blast disease in Nigeria. Nigerian Agric J., 11:170-3.

Babar LK, Iftikhar T, Khan HN, Hameed MA, 2011. Agronomic trials on sug ar cane crop under Faisalabad conditions, Pakistan. Pak. J. Bot., 43(2): 929-935.

Bandeira and Silva, 2006, D.A. Bandeira, O.R.R.F. Silva Aproveitamento de resíduos W. Andrade (Ed.), O sisal do Brasil, Sindifibras, Salvador (2006), pp. 56-61.

Debnath M, Pandey M, Sharma R, Thakur G.S, Lal P, 2010.Biotechnological intervention of Agave sisalana : a unique fiber yielding plant with medicinal Property J. Med. Plants Res., 43 (2010), pp. 177-187.

FAO, 2012. Food and Agriculture Organization of the United Nations. Animal Feed Resources Information System. Food and Agriculture Organization of the United Nations. Animal Feed Resources Information System. recommended.

research work. Special thanks go to Dr TARLA Divine Nfor, to Dr YODA Aristide and Dr KOITA Kadidia for critical reading of the manuscript.

http://www.fao.org/ag/AGA/AGAP/FRG/AFRIS/D ata/350. HTM

FAO, 2013. World Food situation. FAO papers. Rome, Italie.3p.

Gohel NM, Chauhan HL, Mehta AN, 2008. Bio-efficacy of fungicides against Pyricularia oryzae the incitant of rice blast. J. Plant Dis. Sci., 3(2): 189-192.

Iftikhar T, Babar LK, Zahoor S, Khan NG, 2010. "Best Irrigation Management Practices In Cotton" Pak. J. Bot., 42(5): 3023-3028.

Jia Y, McAdams SA, Bryan GT, Hershey HP, Valent B, 2000. Direct interaction of resistance gene and avirulence gene products confers rice blast resistance. The EMBO Journal, Vol.19, No.15, (August 2000), pp. (4004-4014), ISSN 14602075.

Judith Hubert, Robert B, Mabagala, Delphina P. Mamiro, 2015. Efficacy of Selected Plant Extracts against Pyricularia grisea, Causal Agent of Rice Blast Disease . American Journal of Plant Sciences, 2015, 6, 602-611 Article published 12 March 2015.

MAFF ,2012 (Editor). Rice-epidemic region and yield loss., Statistics and Information Department (eds.), The Ministry of Agriculture, Forestry and Fisheries of Japan (MAFF), Tokyo.

Oh YY,2007. Genome-wide transcription studies on infection structure formation and function in Magnaporthe grisea. Ph.D. Dissertation, North Carolina State University, pp. 142.

Ou SH,1985. Rice disease (2). Commonwealth Mycological Institute, ISBN 0851985459.

Ribot C, Hirsch J, Balzergue S, Tharreau D, Notteghem JH,. Lebrun MH, Morel JB. 2008. Susceptibility of rice to the blast fungus, Magnaporthe grisea. J. Plant Physiol. 165: 114-24.

PROTA, 2012. PROTA 4U web database. Plant resources of Tropical Africa. PROTA. http://www.prota4u. 

blast

PubMed, 2011. Department of Pharmacognosy, Bis College of Pharmacy, Gagra, Moga, India.

Journal of Advanced Pharmaceutical Technology \& Research 03/2011; 2(1):3-8.

Séré $Y$, Fargette $D$, Abo M E, Wydra K, Bimerew M Onasanya A and Akator S K, 2013. Managing the Major Diseases of Rice in Africa.16p.

Sere Y, Onasanya A, Afolabi A ,Mignouna HD, Akator K ,2007. Genetique diversity of the blast fungus, Magnaporthe grisea (Hebert) Barr, in Burkina Faso African Journal of Biotechnology vol6 (22) $p$.

Somda I, Leth V, Sereme P, 2007. Antifungal Effect of Cymbopogon citratus, Eucalyptus camaldulensis and Azadirachta indica Oil Extracts on Sorghum Seed-Borne Fungi. Asian Journal of Plant Sciences, 6: 1182-1189. 